\title{
CAN RTK GPS BE USED TO IMPROVE GADASTRAL INFRASTRUCTURE?
}

\section{Volker Janssen ${ }^{1}$, Thomas Grinter ${ }^{1}$, and Craig Roberts ${ }^{2}$}

Survey Infrastructure and Geodesy

NSW Land and Property Management Authority, 346 Panorama Avenue,

Bathurst NSW 2795, Australia

School of Surveying and Spatial Information Systems

The University of New South Wales, Sydney NSW 2052, Australia

Email: Volker.Janssen@lpma.nsw.gov.au , Thomas.Grinter@lpma.nsw.gov.au*, and c.roberts@unsw.edu.au²

\section{ABSTRACT}

Cadastral surveying is concerned with the process of gathering evidence in the form of position information that is used to define the location of objects or land boundaries for the purposes of identifying ownership and/or the value of land parcels. The advent of Global Navigation Satellite Systems (GNSS), such as the Global Positioning System (GPS), has revolutionised the way 3dimensional positions are determined and GPS surveying techniques, particularly Real Time Kinematic (RTK), are increasingly being adopted by cadastral surveyors. This paper presents a methodology for using RTK GPS observations to improve the existing cadastral survey control infrastructure, based on an extensive survey carried out in New South Wales, Australia. It is shown that accuracies (RMS) of $11 \mathrm{~mm}$ in the horizontal and $34 \mathrm{~mm}$ in the vertical component $(1 \sigma)$ can be achieved for this dataset. Calculated bearings and distances agree very well with the official values derived from the state's survey control database, easily meeting accuracy specifications and survey regulation requirements. $55 \%$ of the unestablished marks surveyed were able to be upgraded to cadastral survey control quality. Enhancements in the GPS survey design would have enabled an even higher percentage of marks to be classified as established, showing that the RTK GPS technique is well suited to improving survey control infrastructure for cadastral surveyors.

\section{KEYWORDS}

cadastre, infrastructure, RTK, GPS, geospatial alliance project, Australia 
This paper is a modified version of the oral presentation made at the XXIV FIG International Congress "Facing the Challenges - Building the Capacity", Sydney, Australia, 11-16 April 2010. Michael Troth, Manager of the Geospatial Alliance Project, and David Green are gratefully acknowledged for assisting with the extensive GPS data collection. Russell Commins of LPMA is thanked for producing Figures 1 and 2.

\section{Introduction}

Cadastral surveying, or land surveying, is primarily concerned with the process of gathering evidence in the form of position information that is used to define the location of objects or land boundaries in a geographic area for the purposes of identifying ownership and/or the value of land parcels. This information supports a jurisdiction's land administration, conveyance or land registration system and is critical in order to establish and maintain a digital cadastral database (DCDB).

In the Australian state of New South Wales (NSW), the Survey Control Information Management System (SCIMS) contains coordinates and related metadata information for survey marks established under the direction of the NSW Surveyor General and is maintained by the NSW Land and Property Management Authority (LPMA), formerly the NSW Department of Lands, for the purposes of cadastral boundary definition, engineering surveys, mapping and a variety of other spatial applications [1].

The terms class and order are familiar to all surveyors and geodesists. The class is a function of the planned and achieved precision of a survey network, dependent on the design, survey practices, instrumentation and reduction techniques used. The order is a function of the class, the conformity with respect to the existing control network and the precision of any transformation process that may be required. Table 1 lists the classes applicable for horizontal survey control in Australia. Classes for vertical control are assigned similarly, distinguishing between levelled and non-levelled marks. Detailed definitions can be found in [2].

\begin{tabular}{c|l}
\hline Point class & \multicolumn{1}{|c}{ Typical applications } \\
\hline 3A & Special high precision surveys \\
2A & High precision national geodetic surveys \\
A & National and state geodetic surveys \\
B & State survey control networks \\
C & Survey coordination projects \\
D & Approximate and lower order surveys \\
E & Approximate and lower order surveys \\
U & Unknown or unreliable \\
\hline
\end{tabular}

Table 1

Horizontal survey control mark classes used in Australia [2]

Established survey marks are classified as Class $\mathrm{C}$ or better in their horizontal position, reflecting sufficient redundancy and checks to guarantee the accuracy of the coordinates [2][3]. While SCIMS also contains lower quality survey marks, only established marks can be used for cadastral surveys. Understandably, due to the large size of NSW, the density of established survey marks varies considerably across the state and there are areas where a higher density of established marks is desired, particularly in regional urban areas.

The advent of Global Navigation Satellite Systems (GNSS), such as the United States' Global Positioning System (GPS), Russia's GLONASS, the European Union's Galileo and China's Compass, has revolutionised the way 3-dimensional positions are determined on and above the Earth's surface. Once initialised, Real Time Kinematic (RTK) GPS becomes a high precision coordinate generator and real world digitiser with the ability to significantly enhance productivity.

Practical considerations for cadastral surveyors using RTK GPS were presented by [4] and the following benefits of the technology were pointed out: 
- Usefulness in finding existing survey marks.

- Positions can be measured in the field in real time and distances derived to compare with plan distances.

- Ability to brace a traverse in difficult terrain where traversing techniques would require many setups with short lines to overcome hills or heavy tree cover, potentially improving loop closure accuracy significantly by reducing the number of setups and short lines.

- Ability to connect to existing survey control over distances considered unfeasible using traversing techniques.

- Ability to easily survey irregular natural boundaries.

LPMA has since revised the Surveying and Spatial Information Regulation [5] to permit RTK techniques to be used over short distances by cadastral surveyors. In order to accommodate the coordinate accuracy achieved by GNSS (i.e. $10 \mathrm{~mm}+1 \mathrm{ppm}$ ), the acceptable accuracy for distance measurements was redefined to $10 \mathrm{~mm}+15 \mathrm{ppm}(1 \sigma)$. The growing CORSnetNSW infrastructure [6]-[7] of permanently operating GNSS reference stations utilises the internet to broadcast correction data which is accessed by users, e.g., via the Next-G mobile phone network. This is a more reliable communications medium than UHF radio, particularly in metropolitan regions. These developments, coupled with the improved usability of modern GNSS equipment, have seen GPS surveying techniques, particularly RTK, being increasingly adopted by cadastral surveyors.

RTK GPS techniques have also been investigated by LPMA for upgrade of the DCDB to survey accuracy in certain regions. A case study in the Penrith area was conducted by [8] to determine the optimal number of control marks required for a given area in order to produce a survey-accurate DCDB.

LPMA is promoting the use of GNSS techniques and has stated that it may decide to update SCIMS with RTK-derived coordinates at an established accuracy (Class C only), if observations to the mark have been made from three independent occupations using at least two separate base stations set on existing established SCIMS marks or surveyed in as part of the primary network [3]. Since RTK observations produce radiations, careful network design and redundancy are required to achieve an acceptable control survey outcome [2].

This paper demonstrates how the RTK GPS technique can be utilised to improve the survey control mark infrastructure available to cadastral surveyors by determining high quality $3 D$ positions for an update of the state's survey control database. While cadastral surveyors are mainly concerned with horizontal position, GNSS observations also provide vertical information. Therefore, this study also investigates the benefit of the RTK GPS technique to improve the quality of the vertical coordinate of the surveyed control marks.

\section{Study Area and Observations}

\subsection{The GAP Project}

In 2005, the Geospatial Alliance Project (GAP) was initiated as a consortium of five councils located in southern NSW, i.e. Bland Shire Council, Coolamon Shire Council, Junee Shire Council, Temora Shire Council as well as Goldenfields Water County Council, which includes the aforementioned council areas (Figure 1). The aim of GAP is to provide best practice spatial information and management services to the alliance members, including spatial data capture, management and maintenance, Geographic Information System (GIS) capabilities, staff training, technical support and building awareness of spatial information. 


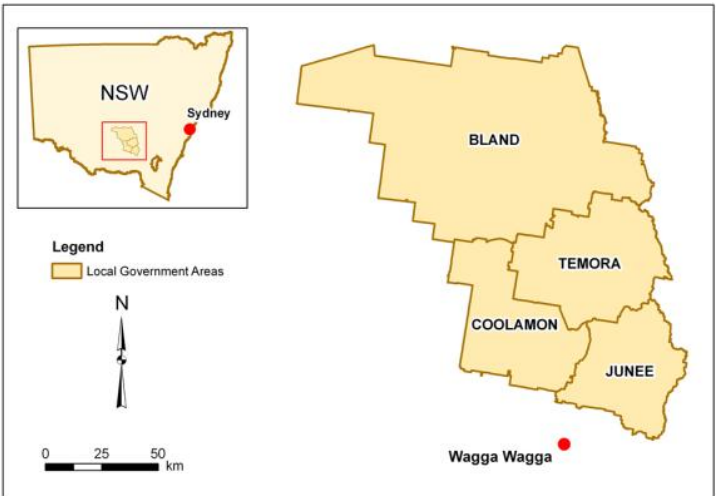

Figure 1

Local government areas involved in the GAP project.

GAP identified the need for an upgrade of survey control marks across the four shire council areas. While numerous survey control marks existed, a large number of these were classified as not established (i.e. less than horizontal Class $\mathrm{C}$ ), making them unusable for cadastral surveys. In order to address this problem and generate an improved foundation for cadastral connections, a multi-year survey (2008-2011) was designed to observe all existing survey marks in the four shire council areas with RTK GPS technology, aiming to upgrade as many unestablished marks as possible to established marks in SCIMS and thereby supporting upgrades to the digital cadastral database (DCDB), engineering and photogrammetric control. The already established marks were to be used to investigate the quality of the survey and the methodology adopted for the cadastral infrastructure upgrade.

\subsection{Study Area and Observations}

This paper presents the results from the GPS survey covering Junee Shire Council (Figure 2), an area of about $2,030 \mathrm{~km}^{2}$, and details the procedure adopted for the SCIMS update process. RTK GPS observations were conducted by a third party after basic training between 15 January and 27 August 2008 using a typical single-base RTK scenario consisting of two (identical) dual-frequency GPS receivers operating at a sampling rate of 1 second and utilising a UHF radio link. The elevation mask for RTK processing was set to $13^{\circ}$, and relative U.S. National Geodetic Survey (NGS) antenna phase centre variation models were applied.

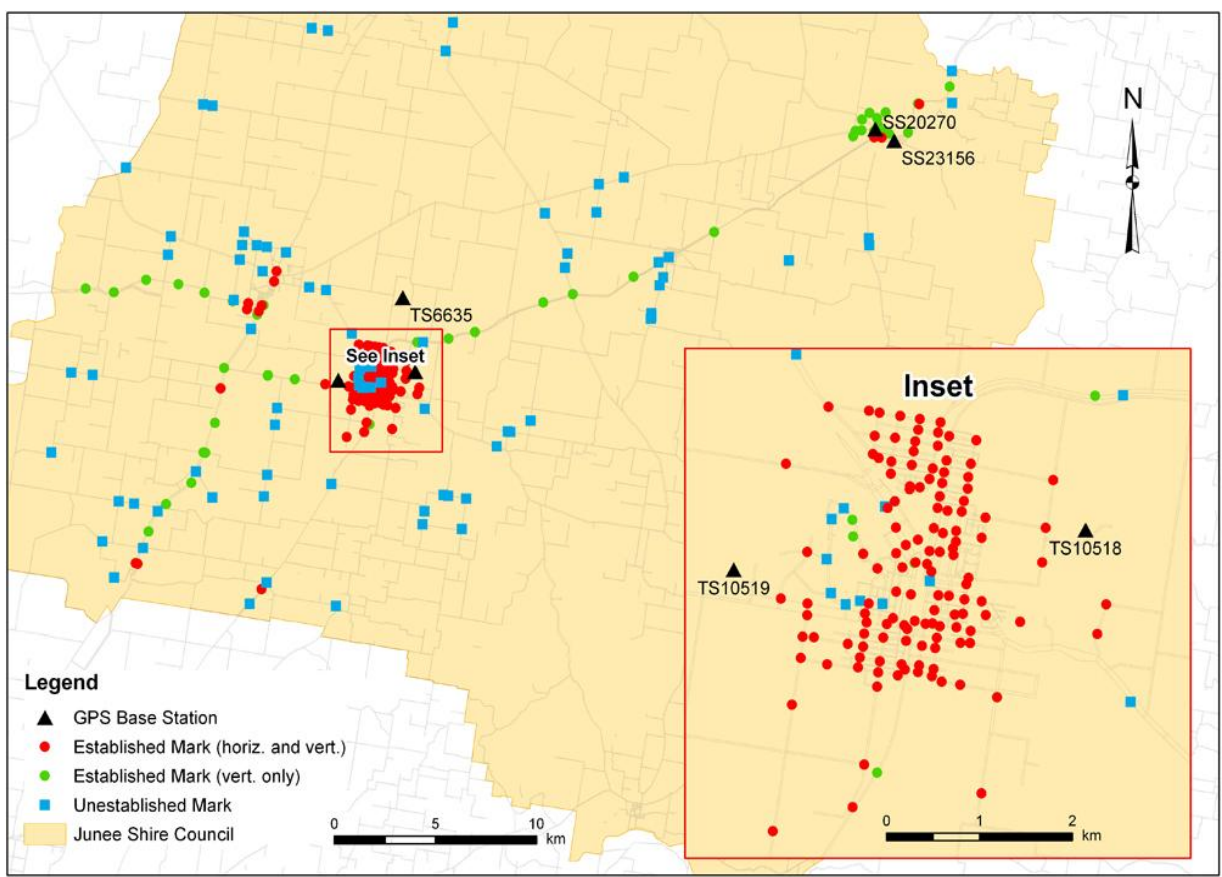

Figure 2

Survey marks occupied with GPS in Junee Shire Council. 


\section{Data Processing and Analysis}

This section details the procedure adopted for data processing and analysis in order to determine high-quality coordinates for the SCIMS update and to investigate the quality of the GPS-derived results.

\subsection{Network Adjustment}

The adjustments are based on the baseline vectors exported from the commercial GPS processing software package utilised, rather than the RTK-derived coordinates. The application of local rotations and scale changes during processing was not necessary. The observed ellipsoidal heights were transformed to the Australian Height Datum 1971 (AHD71) by applying the AUSGeoid98 [9].

\subsubsection{Minimally constrained adjustment}

The GPS dataset consisted of two unconnected sections (see Figure 2). Firstly, a minimally constrained adjustment was performed holding only one base station in each section fixed (TS6635 and SS20270). The network was processed using the Geolab 2001 version 2001.9.20.0 adjustment software [10] and initially consisted of 269 stations and 776 separate GPS baselines.

The initial observation weightings for the minimally constrained adjustment are summarised in Table 2. Geolab combined these with the RTK baselines' variancecovariance (VCV) information to produce final baseline component weights.

Table 2

Initial GPS baseline weighting.

\begin{tabular}{lcccc}
\hline & STD & ppm & Centring from & Centring to \\
\hline Horiz. component & $5 \mathrm{~mm}$ & 0.7 & $1.5 \mathrm{~mm}$ & $1.5 \mathrm{~mm}$ \\
Vert. component & $5 \mathrm{~mm}$ & 0.7 & $2.0 \mathrm{~mm}$ & $2.0 \mathrm{~mm}$ \\
\hline
\end{tabular}

The statistical results of the minimally constrained adjustment for the highly radial survey were used to check for any gross errors in the network. After investigation, 23 baselines with unrealistically large residuals had to be removed, constituting about $3 \%$ of the observations. The resulting adjustment failed with a variance factor (VF) of 1.31, flagging 13 outliers which were analysed and indicated contradictory GPS observations. These flagged residuals were noted and further analysed in the fully constrained adjustment. It should be noted that the standard deviations of the GPS observations used in the minimally constrained adjustment were too optimistic and therefore revised in the fully constrained adjustment.

\subsubsection{Fully constrained adjustment}

In addition to the five base stations (all classified horizontally as 2A0, i.e. Class $2 \mathrm{~A}$ and Order 0 ), 141 stations were held fixed in the horizontal component (Table 3 ). In a first adjustment run, only the stations classified as $2 \mathrm{~A} 0$ and $\mathrm{A} 1$ were held fixed, and the coordinates of a sample group of about 20 points were investigated. In a second run, the stations classified as B2 were also held fixed, and the resulting coordinates of the sample set were compared to their initial values. Since all differences remained below $10 \mathrm{~mm}$, the fixed B2 control was left in the adjustment, allowing it to be highly constrained. Due to the adjustment being based on radiations, this is highly desirable when additional ground observations are to be added. It should be noted that there was no existing $\mathrm{C} 3$ horizontal control in the study area. 
Point class/order

No. of fixed stations

$\begin{array}{lc}2 \mathrm{~A} 0 & 9 \\ \mathrm{~A} 1 & 61 \\ \mathrm{~B} 2 & 76\end{array}$

Table 3

Horizontal constraints.
The network contained 184 marks with AHD71 heights of C3 or better, resulting in an orthometric height constraint for $68 \%$ of the stations. The weighting of these orthometric heights was based upon the marks' class and order in SCIMS, which also considers the higher quality of the levelling technique for heighting (Table 4). It is worth noting that the GPS base stations were all classified as LCL3 (i.e. levelled) in the vertical component, except TS6635 which was B3 (i.e. GPS-derived with less than ideal control).

\begin{tabular}{cc}
\hline Point class/order & Uncertainty \\
\hline LAL1 & $1 \mathrm{~mm}$ \\
LBL4 & $1 \mathrm{~mm}$ \\
LCL3 & $1 \mathrm{~mm}$ \\
B2 & $10 \mathrm{~mm}$ \\
B3 & $30 \mathrm{~mm}$ \\
C3 & $30 \mathrm{~mm}$ \\
\hline
\end{tabular}

Initially the GPS observation weightings listed in Table 2 were applied, holding all of the established marks (Class $C$ or better) within the adjustment fixed horizontally and constrained vertically. It was determined that the GPS observation weightings were too optimistic and had to be loosened, so a new weighting scheme was devised based on a combination of the manufacturer's specifications and previous RTK GPS experience (Table 5). The uncertainty in centring was revised to account for the 2-metre pole with attached bubble being used in the survey.

\begin{tabular}{lcccc}
\hline & STD & ppm & Centring from & Centring to \\
\hline Horiz. component & $10 \mathrm{~mm}$ & 1.0 & $3 \mathrm{~mm}$ & $5 \mathrm{~mm}$ \\
Vert. component & $30 \mathrm{~mm}$ & 3.0 & $3 \mathrm{~mm}$ & $3 \mathrm{~mm}$ \\
\hline
\end{tabular}

In order to increase the number of unestablished marks to be upgraded to established marks, additional information obtained from Deposited Plans (DPs) was included to supplement the adjustment (see section 3.1.3).

The fully constrained adjustment passed with a VF of 0.99 , however 18 residuals were flagged as outliers. In addition, a further 43 baselines were found to have high residuals of $>50 \mathrm{~mm}$. Analysis of the affected baselines identified a problem at one of the base stations. Large variations $(>100 \mathrm{~mm})$ were evident in the baseline observations utilising TS10518 as base station on 5-6 March compared to the other days of the survey. Due to a lack of additional information, the source of these variations (e.g. maladjusted tribrach or incorrect setup) could not be determined. Therefore, all baselines from TS10518 on 5-6 March were removed, fortunately amounting to only 39 observations which represents $5 \%$ of the survey. In addition, one ground observation obtained from a DP was removed due to large residuals. It is worth noting that it was later found that this particular observation was actually erroneous in the DP.
Table 4

Orthometric height constraints.
Table 5

Final GPS baseline weighting. 
The final adjustment contained 714 GPS baselines and failed with a VF of 0.67 , suggesting that a tightening of the observation uncertainties was required. However, the VFs for ellipsoidal and orthometric height were determined to be 0.91 and 0.81 , respectively, and the result was therefore deemed satisfactory. Hence, no scaling of the VCV matrix by the VF was adopted.

Five residuals were flagged in the adjustment but were deemed acceptable since these referred to constrained orthometric heights. In all five cases, at least three GPS observations were made to each mark. The values agree with each other, but disagree with the orthometric height for the mark by up to $125 \mathrm{~mm}$, indicating a possible incorrect orthometric height for these marks. However, further analysis of each mark is required to confirm this.

All of the 13 residuals that were flagged in the minimally constrained adjustment (see section 3.1.1) passed in the fully constrained adjustment due to the larger observation uncertainties applied. However, closer inspection revealed that the GPS observations to each of these flagged marks disagree. The observations were left in the adjustment but the larger residuals were later taken into account when the affected marks were assigned an order (see section 4).

Overall, the GPS residuals were relatively small, typically less than $50 \mathrm{~mm}$ in each Cartesian coordinate component. The residuals of the 88 ground observations obtained from DPs were typically less than 10 " and $20 \mathrm{~mm}$, comparing well with the accuracy of $10 \mathrm{~mm}+15 \mathrm{ppm}(1 \sigma)$ required for a distance measurement by Clause 25 of the Surveying and Spatial Information Regulation 2006 [5].

\subsubsection{Additional information obtained from Deposited Plans}

A Deposited Plan (DP) most commonly depicts a subdivision of a land parcel and outlines any easements or restrictions on the land. In defining new parcel boundaries, this plan creates the legal identity of the land once it is registered with LPMA.

In order to add information to the GPS observations in the adjustment, ground observations obtained from DPs were utilised. The observed directions and distances between the marks were reduced to the ellipsoid. One of the purposes of the GAP project is to upgrade unestablished marks to established marks. In order to achieve this using GNSS surveying techniques, three baselines from at least two different base stations must be observed [11]. Adding an observed ground connection between marks to the adjustment enabled an upgrade of many marks that were only observed twice by GPS.

In total, 88 observations from 31 DPs, connecting 66 points, were added to the fully constrained adjustment. The observation weightings are based on similar adjustments previously performed by LPMA (Table 6).
Table 6

Weighting of ground observations derived from DPs.

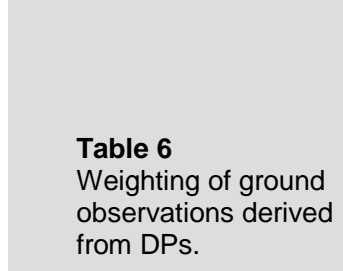

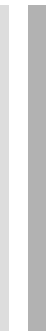

\begin{tabular}{lcccc}
\hline & STD & ppm & $\begin{array}{c}\text { Centring } \\
\text { from }\end{array}$ & Centring to \\
\hline Direction & $8 ”$ & - & $2.5 \mathrm{~mm}$ & $2.5 \mathrm{~mm}$ \\
Distance & $10 \mathrm{~mm}$ & 20 & $2.5 \mathrm{~mm}$ & $2.5 \mathrm{~mm}$ \\
\hline
\end{tabular}

\subsection{Absolute Accuracy: RTK vs. SCIMS on Established Marks}

In order to investigate the absolute accuracy of the RTK GPS campaign and the presented methodology for cadastral infrastructure improvement, the calculated coordinates of all established marks in the survey were compared to their published SCIMS values. A constrained adjustment of the GPS network was performed, holding only the five GPS base stations fixed in the horizontal and constrained in the vertical component. The GPS observation weightings listed in Table 5 were applied, and no DP directions or distances were utilised. 
As mentioned earlier, 141 of the surveyed marks were already established in both the horizontal and vertical component, while 43 were established only vertically. By running an adjustment that allows these established marks to float, a comparison can be made between the coordinates of these marks determined by the RTK GPS survey and their SCIMS values. Under the assumption that RTK GPS accuracy and the horizontal and vertical datums are relatively uniform across the study area, this will also give an indication of the quality of the presented methodology to upgrade unestablished marks using RTK GPS.

The adjustment achieved a VF of 0.41 and failed the chi-square test, suggesting that the input variances should be tightened. However, as this adjustment is being used for comparison purposes, this result was accepted. Two residuals were flagged but deemed acceptable since they referred to constrained orthometric heights, indicating a possible error in the orthometric height in SCIMS (cf. section 3.1.2).

Table 7 shows the differences between the GPS-derived coordinates and their SCIMS values. It is recognised that the differences may in part be due to the inferior quality of the observations used to establish these marks in the era before satellite positioning, although routine NSW survey control practices were followed at the time. The comparison exceeded expectations with a Root Mean Square (RMS) of $11 \mathrm{~mm}$ in the horizontal and $34 \mathrm{~mm}$ in the vertical component $(1 \sigma)$, indicating that the RTK GPS technique is well suited to improve survey control infrastructure for cadastral surveyors.

\begin{tabular}{lcccc}
\hline & Easting & Northing & Horizontal & Vertical \\
\hline RMS & $7 \mathrm{~mm}$ & $8 \mathrm{~mm}$ & $11 \mathrm{~mm}$ & $34 \mathrm{~mm}$ \\
Min. & $-18 \mathrm{~mm}$ & $-25 \mathrm{~mm}$ & $0 \mathrm{~mm}$ & $-65 \mathrm{~mm}$ \\
Max. & $29 \mathrm{~mm}$ & $36 \mathrm{~mm}$ & $36 \mathrm{~mm}$ & $137 \mathrm{~mm}$ \\
\hline
\end{tabular}

It should be noted that the difference in the vertical component exceeded $+100 \mathrm{~mm}$ in seven cases. As previously mentioned, this indicates a possible problem with the orthometric heights of these marks given in SCIMS, as the GPS observations agree well with each other. Most of these marks are clustered in a group of four (B2, based on GPS observations in 1997/98) and a group of two (LAL1, optical levelling based on the same run), while the remaining mark is classified as LBL4 (i.e. optically levelled with less than ideal control). Further research is necessary in order to identify the cause of this discrepancy, which could, for instance, be due to local distortions in the geoid or weak levelling connections. However, this is beyond the scope of this paper. Removing these seven values reduced the RMS in the vertical component to $26 \mathrm{~mm}$.

\subsection{Relative Accuracy: RTK vs. SCIMS over Short Distances}

The relative accuracy of the RTK GPS results was investigated by determining the bearing and grid distance between 50 established marks, based on the initial, unadjusted RTK-derived coordinates as well as the given SCIMS coordinates. In order to pay particular attention to short distances routinely encountered by cadastral surveyors, the selected dataset contained distances ranging from $28 \mathrm{~m}$ to $332 \mathrm{~m}$. Table 8 summarises the differences between the RTK-derived and SCIMS-derived values, based on a total of 51 bearing and distance pairs.

\begin{tabular}{|l|c|c|}
\hline & Grid Distance & Bearing \\
\hline RMS & $9 \mathrm{~mm}$ & $14 "$ \\
\hline Min. & $-30 \mathrm{~mm}$ & $-33 "$ \\
\hline Max. & $14 \mathrm{~mm}$ & $33 "$ \\
\hline
\end{tabular}

It is evident that the values agree very well, with RMS values of $9 \mathrm{~mm}$ for the grid distance and 14" for the bearing $(1 \sigma)$. Figure 3 illustrates the entire dataset (absolute
Table 7

Difference between RTK GPS and SCIMS coordinates.
Table 8

Difference between values derived from RTK GPS and SCIMS coordinates. 
differences) as a function of the distance between the two marks involved in the calculation. The Surveying and Spatial Information Regulation 2006 stipulates the required accuracy for a distance measurement as $10 \mathrm{~mm}+15 \mathrm{ppm}$ or better $(1 \sigma)$ [5]. This translates into $11 \mathrm{~mm}$ over $50 \mathrm{~m}$ and $14.5 \mathrm{~mm}$ over $300 \mathrm{~m}$, and is easily met by the RTK GPS results. The bearing differences also show the consistency of the RTKderived values. For instance, bearing errors of 15 " over $100 \mathrm{~m}, 10$ " over $200 \mathrm{~m}$ and 5" over $300 \mathrm{~m}$ result in horizontal position errors of $7.3 \mathrm{~mm}, 9.7 \mathrm{~mm}$ and $7.3 \mathrm{~mm}$, respectively.

Figure 3

RTK-derived distances and bearings vs. SCIMS (absolute differences).

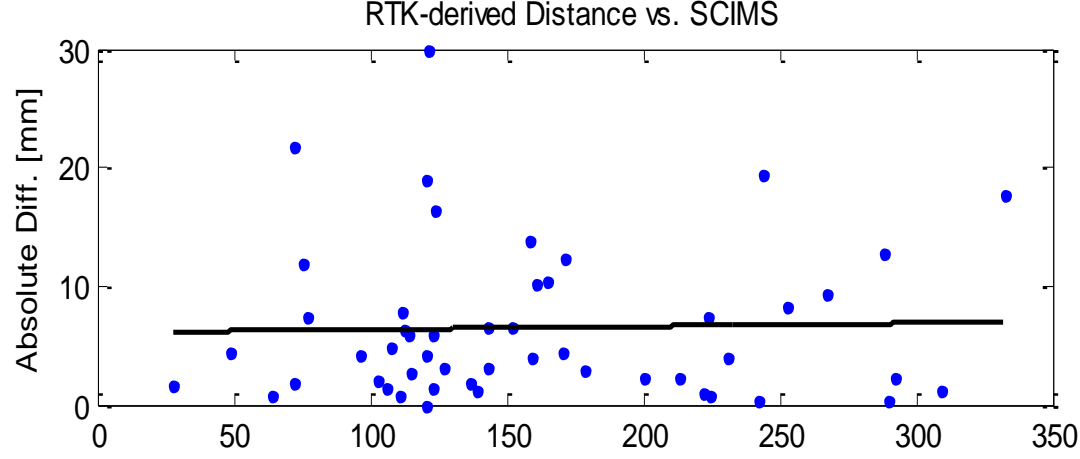

RTK-derived Bearing vs. SCIMS

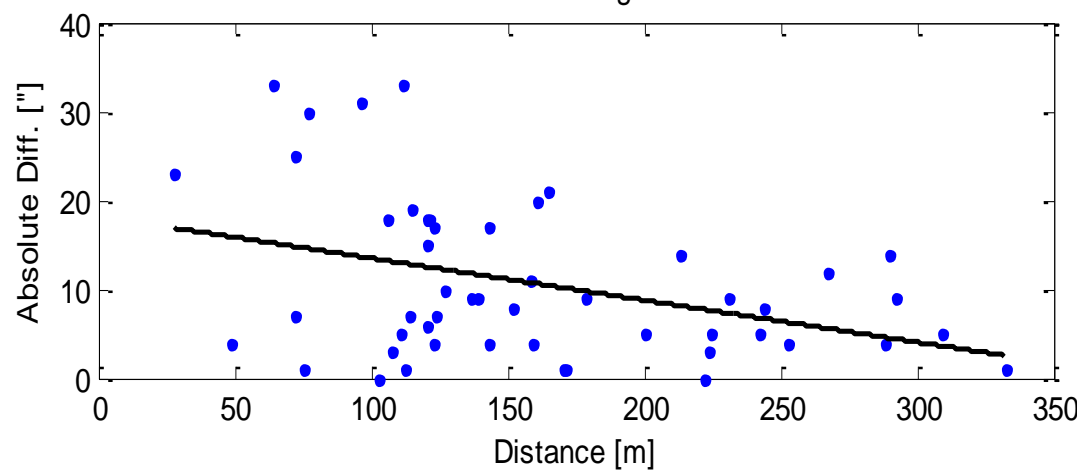

Linear trend lines are also shown in Figure 3, however it must be emphasised that these are not statistically sound and can therefore only give an indication. The accuracy of the RTK-derived distances is very consistent, reflecting, in part, the local homogeneity of the Geocentric Datum of Australia (GDA94) and the uniform atmospheric conditions encountered in the study area. It should be noted that a similar accuracy can be expected over longer distances calculated in the study area since the differences reflect the quality of the RTK GPS observations, which is influenced by the baseline length between each mark and the base station(s) utilised as well as the network geometry, and not the distance between the two marks involved in the distance calculation. As expected, the quality of the RTK-derived bearings improves over longer distances since errors in the horizontal position have a lesser effect on the calculated bearing.

\section{Upgrade of Cadastral Survey Control}

The main purpose of this study was to upgrade as many as possible of the observed unestablished marks to established marks in order to improve the survey control infrastructure available in the study area. Since GNSS observations provide 3dimentional positioning information, the vertical component was included in the upgrade. According to the regulations, it is required that at least three baselines are observed from at least two separate base stations in order to upgrade an unestablished mark using RTK GNSS methods [5],[ 3], [11].

It was determined that 55 marks met this requirement: 37 to be upgraded to Class $C$ in both the horizontal and vertical components, and 18 to be upgraded in the horizontal component (as they were already established in the vertical). However, five of these 
marks were excluded from the upgrade due to discrepancies in the GPS observations identified during the adjustment (see section 3.1.2). Therefore, 50 survey control marks met the upgrade criteria: 33 both horizontally and vertically, and 17 in the horizontal component. Unfortunately some of the raw RTK observations had to be removed during the adjustment process (see sections 3.1.1 and 3.1.2), leaving several marks to be observed only once or twice. This could have been avoided with more careful field procedures and better survey design.

A further 22 unestablished marks were observed twice with RTK GPS. By adding one or two ground observations obtained from DPs (see section 3.1.3), these also met the criteria to become established. One of these marks was excluded from the upgrade due to previously identified discrepancies in the GPS observations, leaving 21 additional marks to be upgraded to Class $C$ (13 in both the horizontal and vertical components, and 8 horizontally only since they were already established vertically).

The remaining 51 unestablished marks were observed only once or twice with RTK GPS and suitable DP information was not available. The majority of these marks were initially classified as Class $U$ in both the horizontal and vertical components, with eight marks being Class $\mathrm{E}$ either horizontally or vertically. Although these marks cannot be upgraded to established marks, it is possible to increase their class and order based on the GPS survey. All of the marks with two RTK GPS occupations were updated to Class $\mathrm{D}$ in both coordinate components (making them suitable for DCDB upgrades), while the five marks occupied only once were updated to Class $E$ in both components.

The six unestablished marks that were initially excluded from the upgrade due to GPS observation discrepancies were updated to Class $E$ in both components. Hence, all of the 128 surveyed unestablished marks could either be established to Class C (55\%) or at least be updated to Class $D$ or $E(45 \%)$, resulting in a significant improvement of the cadastral survey infrastructure in the study area.

\section{Concluding Remarks}

This paper has presented a methodology for using RTK GPS observations to improve the existing cadastral survey control infrastructure, based on an extensive survey carried out in Junee Shire Council, New South Wales, as part of the Geospatial Alliance Project (GAP). Of the 128 unestablished marks surveyed, $55 \%$ were able to be upgraded to established marks of Class $\mathrm{C}$, while the quality of the remaining marks was updated to Class D or E. Improvements in the GPS survey design and more careful field procedures would have enabled an even higher percentage of marks to be classified as established. However, it should be remembered that this survey was carried out by inexperienced GNSS users and the lessons learnt will be of great benefit as the GAP project continues across the remaining council areas. It was found that ground observations obtained from Deposited Plans (DPs) provided valuable additional information for the adjustment.

The large number of already established marks surveyed enabled a thorough analysis of the accuracy achieved with the RTK GPS technique. The RTK positions of the established marks were compared against their SCIMS values, exceeding expectations with an accuracy (RMS) of $11 \mathrm{~mm}$ in the horizontal component and 34 $\mathrm{mm}$ in the height component $(1 \sigma)$. In addition, the relative accuracy of the RTK GPS results was investigated by determining the bearing and grid distance between a subset of established marks. Of particular interest were short distances routinely encountered by cadastral surveyors, and it was shown that the results agreed very well with the values derived from SCIMS, easily meeting accuracy specifications stated in the Surveying and Spatial Information Regulation 2006.

The RTK GPS technique is well suited to improving survey control infrastructure for cadastral surveyors and has the potential to detect erroneous DP information. The ongoing expansion and densification of Continuously Operating Reference Station (CORS) networks, such as GPSnet [12] in Victoria and CORSnet-NSW [13], [7] in New South Wales, will further improve position accuracy and RTK range capabilities by providing Network RTK services [14]-[15]. CORSnet-NSW, for instance, currently consists of about 50 GNSS reference stations and will be expanded to at least 70 stations by 2012. This infrastructure will provide cadastral surveyors with increasingly fast and easy access to highly accurate survey control, eliminating the need for 
surveyors to operate their own base station and thereby improving productivity. The presented methodology for updating existing survey control marks based on RTK GPS observations will also benefit from the increased number of CORS across the state, potentially removing the need for a temporary base station. 


\section{REFERENCES}

[1] Land and Property Management Authority, SCIMS online. [Online]. Available: http://www.lpma.nsw.gov.au/survey_and_maps/scims [Accessed Nov. 3, 2010].

[2] Intergovernmental Committee on Surveying and Mapping, "Standards and practices for control surveys (SP1)," version 1.7, 2007. [Online]. Available: http://www.icsm.gov.au/icsm/publications/sp1/sp1v1-7.pdf [Accessed Nov. 9, 2010].

[3] New South Wales Department of Lands, "Control surveys and SCIMS: What is acceptable?," 2007. [Online].Available: http://www.lpma.nsw.gov.au/survey_and_maps/surveying/survey_information [Accessed Nov. 15, 2010].

[4] C. Roberts, "GPS for cadastral surveying: Practical considerations," in Proceedings of SSC 2005, Melbourne, Australia, 2005.

[5] New South Wales Government. "Surveying and spatial information regulation 2006," [Online].Available: http://www.legislation.nsw.gov.au/maintop/view/inforce/subordleg+530+2006+cd+0+N [Accessed Nov. 19, 2010].

[6] Land and Property Management Authority, CORSnet-NSW website. 2010. [Online]. Available : http://corsnet.lpma.nsw.gov.au [Accessed Nov. 3, 2010].

[7] V. Janssen, A. White, and T. Yan, "CORSnet-NSW: Towards state-wide CORS infrastructure for New South Wales, Australia," in Proceedings of the $24^{\text {th }}$ FIG International Congress, Sydney, Australia, pp. 1-14, 2010.

[8] D. Watkins, "Optimising survey control using GNSS RTK \& CORS networks for spatially upgrading the DCDB - A case study in the Penrith area," M.S. thesis, School of Surveying and Spatial Information Systems, University of New South Wales, Sydney, Australia 2007.

[9] W. E. Featherstone, J. F. Kirby, A. H. W. Kearsley, J. R. Gilliland, G. M. Johnston, J. Steed, R. Forsberg, and M. G. Sideris, "The AUSGeoid98 geoid model for Australia: Data treatment, computations and comparisons with GPS-levelling data," Journal of Geodesy, vol. 75, pp. 313-330, 2001.

[10] Microsearch Corp, Geolab software. 2010. [Online]. Available: http://www.msearchcorp.com/Products/GeoLab/ [Accessed Nov. 26, 2010].

[11] Land and Property Management Authority, "Surveyor General's Direction No. 9: GNSS for cadastral and mining surveys (draft)." Available : http://www.lpma.nsw.gov.au/about us/publications/guidelines/surveyor generals directions [Accessed Nov. 3, 2010].

[12] M. Hale, P. Ramm, and J. Wallace, "Legal positions and Victoria's GPSnet," in Proceedings of SSC 2007, Hobart, Australia, pp. 163-176, 2007.

[13] A. White, T. Yan, V. Janssen, and K. Yates, "CORSnet-NSW: Delivering a state-of-the-art CORS network for New South Wales," in Proceedings of IGNSS 2009, Surfers Paradise, Australia, pp. 7, 2009.

[14] V. Janssen, "A comparison of the VRS and MAC principles for network RTK," in Proceedings of IGNSS 2009, Surfers Paradise, Australia, pp. 13, 2009.

[15] D. Norin, G. Hedling, D. Johansson, S. Persson, and M. Lilje, "Practical evaluation of RTCM network RTK messages in the SWEPOS network," in Proceedings of ION National Technical Meeting, Anaheim, California, pp. 353-359, 2009. 